\title{
METHODS OF COMPARISON OF THE ECONOMIC ORDER QUANTITY AND JUST-IN-TIME RESTOCKING TECHNOLOGIES. THE CASE STUDY
}

Andrii Galkin ${ }^{1}$, Velerii Levada², Volodymyr Kyselov ${ }^{3}$, Oksana Hulchak ${ }^{4}$, Dmytro Prunenko ${ }^{1}$, Iryna Voronko ${ }^{5}$

${ }^{1}$ Department of Transport System and Logistics, Transport System and Technologies Faculty, O. M. Beketov National University of Urban Economy in Kharkiv, Kharkiv, Ukraine

${ }^{2}$ Kharkiv Customs Office of the Ministry of Revenue and Duties of Ukraine, Kharkiv, Ukraine

${ }^{3}$ Educational - Research Institute of Municipal Administration and Urban Development, Tavrida National V. I.

Vernadsky University, Kyiv, Ukraine

${ }^{4}$ Department of Transport Systems and Road Safety, National Transport University, Kiev, Ukraine

${ }^{5}$ Technology of Aircraft Manufacturing Department National Aerospace University "Kharkiv Aviation Institute",

Kharkiv, Ukraine

*E-mail of corresponding author: galkin.tsl@gmail.com

\section{Resume}

Estimation of the optimal size of order is one of the key tasks in determining the parameters of the urban freight restocking system. The existing analytical models and methods are considering each technology separately and they do not compare the Economic Order Quantity (EOQ) and Justin-tme (JIT) restocking technologies. The purpose of this research was to evaluate efficiency of the JIT and EOQ restocking technologies. The research would help in selecting the delivery model, analyzing functioning of existing JIT and EOQ models. The article presents an approach to determining the comparison in organizing supplies to the retailer. For this, the two supply models were compared. The Just-in-Time model is characterised by costs that are spend on transportation. The Economic Order Quantity model includes costs of transportation and storage in a warehouse. After calculations, application of the Just-in-Time model in the given conditions was determined.

Available online: https://doi.org/10.26552/com.C.2022.2.A35-A43

\section{Article info}

Received 25 May 2021

Accepted 24 September 2021

Online 22 December 2021

\section{Keywords:}

goods delivery

economic order quantity (EOQ)

model

just-in-time (JIT) model

ISSN 1335-4205 (print version)

ISSN 2585-7878 (online version)

\section{Introduction}

The economic order quantity (EOQ) determines the replenishment frequency for strategies that regulate size of order and its frequency [1]. In this case, the estimation of EOQ is accompanied by caculation of the safety stock. Conventional approaches imply a separate definition of these indicators, which can lead to adoption of their erroneous values. The reason for this is interdependence of the order size and safety stock. Thus, increasing in the orders size leads, on the one hand, to reducing in the frequency of replenishment of stocks and, as a result, to increase in the amplitude of fluctuations in demand for period between the two successive deliveries and losses from the deficit, which must be compensated by increasing a stock. On the other hand, according to the patterns of folding random variables, the longer period between the two successive deliveries, leads to the smaller value of variation coefficient of demand, which leads to deficit [2]. In addition, most methods for determining the EOQ are based on the lack of influence of orders size on replenishment costs.
In practice, this assumption is only partially valid, in terms of having some kind of overhead for processing and receiving an order. The greater part of the stocks replenishment costs significantly depend on costs of transporting, which depends on the consignment size and the carrying capacity of vehicle [3]. Such an assumption is not at all obvious and reliable. The costs of delivering a new shipment to the warehouse may amount to a significant share of the inventory management costs, many times over the costs of storing stocks [4]. Especially noticeable impact of the orders quantity on the stocks replenishment costs during the goods delivery by trucks and in particular for delivery over long distances. Another aspect related to this issue is determination of the unit costs of storing goods [5]. Accurate determination of the unit costs of storing goods through rent shows that they are substantially less than the costs of immobilization of funds. In connection with the above, the relevance of the solution to this problem should be noted.

The article describes comparison of the two technologies - EOQ and JIT. The article contains the 
following sections: Introduction; Literature review where a deeper analysis of the current state of research in this area is given; Research method where the methodology of research is presented; Research section present simulation in the second biggest Ukrainian city of Kharkiv; the differences between the classic model and real technological circumstances; the patterns of EOQ and JIT behavior on logistics parameters. the final two sections Discussion and Conclusions are supporting and verifying obtained results.

\section{Analysis and statement of the research problem}

The first works devoted to determining the EOQ, appeared almost a century ago [6]. However, even now the models proposed at that time still underlie modern methods for determining this parameter. The classical Wilson's model [6] uses the fixed costs per order and fixed holding costs. In the last decades, a lot of scientists paid attention to comparison of different logistic models. The EOQ has couple of assumptions:

- resource consumption is continuous and uniform;

- the period between two adjacent deliveries is constant;

- demand is met completely and instantly;

- transit and insurance stocks are absent;

- $\quad$ storage capacity is not limited;

- costs for placing and executing the order do not depend on the size of the order and are constant during the planning period;

- the price of products supplied is constant during the planning period;

- the costs of maintaining stocks of a unit of production during a unit of time are constant and do not depend on the amount invested in stocks of funds and terms. The above assumptions impose many limitations of a practical nature, without which the reliability of the calculations according to this formula is in serious doubt. To overcome some limitations, attempts have been made to change the calculation algorithm. With such a change it became possible to analyze the system of discounts, a variant of the formula with replenishment of stocks for some time [7], calculation of the size of delivery on the eve of the expected increase in purchase prices and others.

However, many questions remain unanswered, among them the following: in real conditions, the delivery party depends on the delivery technology and warehousing technology, which are variable characteristics depending on the volume of traffic [8]. Even different quntity with the same technology cause a change in the costs of delivery, which are to change the load capacity of the vehicle, which affects the costs of transport services, as well as the costs of chanting depends on the demand affecting the lease area and the number of loading and unloading operations and related technological operations. Therefore, under such circumstances, delivery costs are not a fixed value, but a function that depends on the technological parameters of the logistics system.

Chyr et al. raised the issue of enterprise transition from the EOQ model to JIT model [9]. This decision is a very complicated and requires careful examination [10]. To facilitate the decision making Fazel suggested a mathematical model to compare costs between the EOQ and the JIT system [11]. An indifference point, at which costs were the same, was suggested. Min and Pheng formulate indifference points considering a discount function based on the order quantity [12]. Schniederjans and Cao further argued that a single additional costs item could have a substantial impact on the conclusions [13]. An alternative set of models to those Fazel presented to compare the costs of inventory under EOQ and JIT systems [11]. Campbell and Joshi highlighted that the EOQ model in comparison to the JIT model has inventories and there are opportunities to get some discounts [14]. Some experts described technology of how to apply the JIT system in the company [15]. Paper found influence of variable parameters on result of EOQ model estimation. Basing on proposed approach and collected data the recommendation and decision support can be made for choosing order size in variety external influence [16].

In contrast to the classic model of $\mathrm{EOQ}$, in which the cumulative costs of replenishment and storage of stocks are the criterion, the author of [17] proposes to use profitability and income]. However, income and profitability, which also depend on price of the product, demand, etc. change on marketing conditions. Therefore, size of the order may change simultaneously, frequently and quickly. In this case, the practical implementation of this method is very problematic, since the frequency of deliveries must be agreed with the supplier and a positive solution to this issue.

The analysis of scientific approaches to determining the restocking technologies and the safety stock showed connection to various details, but poorly connecting with technological specifics of the current supply chain. Variation of the costs of delivery due to technological changes (vehicle capacity, vehicle route problem optimization, handling improvement, etc.) changed the value of $\mathrm{EOQ}$. Therefore, calculation scenario for such an effect is an important theoretical and practical tasks. Moreover, obtained researched data have to be evaluated and assess for further application and comparison of the JIT model and EOQ model. Therefore, the purpose of the research was to evaluate efficiency of the JIT and EOQ restocking technologies. Thus, the specific objectives of this paper were:

1. to develop a method for assessing restock process.

2. to make calculations on different parameters of restocking process and established influence on order quantity;

3. to process the obtained data and compare the results, finding the patterns. 


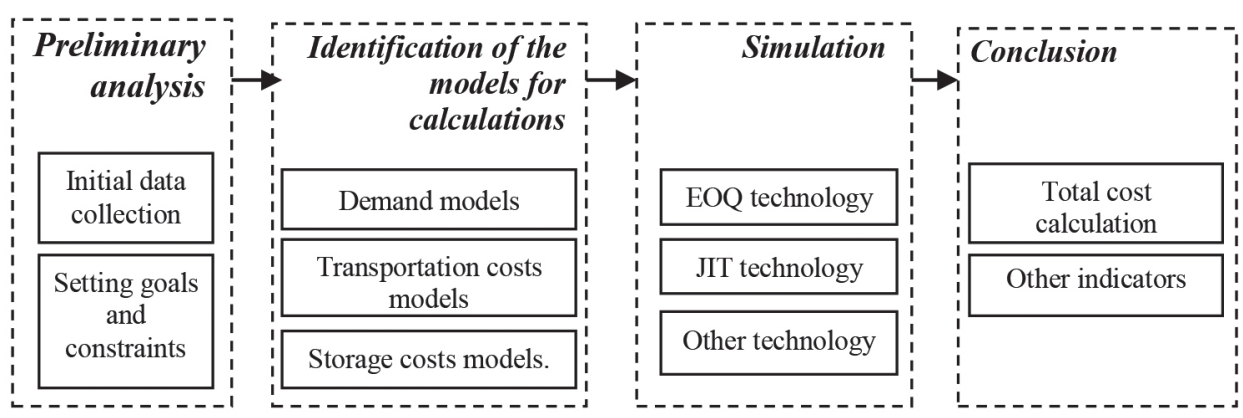

Figure 1 Conceptual framework of the restocking tecnologies

\section{Research method}

The method is divided in four stages (Figure 1).

The overall conceptual approach was described in four stages:

1. The preliminary analysis stage consists of choosing goals of research and collecting the data for futher calculation. Formed database set up the range of variation of the obtained results.

2. Identification of the models for calculations is the second stage. There are different methods and models, which can be used for assessing costs of transportation, storage, capital immobilization or etc. The choosing should meet the objectives of the research and results needed to obtain.

3. The restocking simulation and calculation results are performed on the third stage. The different technologies of restocking give different outcomes [18]. The two restocking technologies, JIT and EOQ, were compared.

4. In the last stage, the total costs were assessed. The results of using the comparing models are based on total costs indicator. In addition, other indicators can be used for evaluating results.

To compare the two models of goods delivery, the total costs per month for each model need to be estimated. For this, the transportation costs and costs of storage in warehouse must be set, which depend on variable costs, constant costs, warehouse space and supply quantity.

Variable costs were determined by formula [19]:

$B_{V C}=0.113 \cdot q_{H}^{0.339}+0.067 \cdot R_{n}^{-0.092}$,

where $q_{n}$ - load capacity of a vehicle, ton; $R_{n}$ - specific fuel consumption of a vehicle, $1 / 100 \mathrm{~km} ; n=1, \ldots, N$ - type of a vehicle by capacity.

Constant costs of the transport process can be defined as follows [19]:

$B_{C}=0.0015 q_{n}^{0.92}+0.0389 A^{-0.095}$,

where $A$ - number of vehicles per route, units.

The transportation costs to the retailers for specific distribution scheme $t$ are:

$$
Z_{t}=B_{V C} \cdot l_{r}+B_{C} \cdot \frac{l_{r}}{v},
$$

where $l_{r}$ - length of the $r$-th route, $\mathrm{km} ; v_{r}$ - technical speed of a vehicle, $\mathrm{km} /$ hour; $r=1, \ldots, R$ - specific type of route.

The storing costs in the retailers are estimated as [20]:

$$
\begin{aligned}
& Z_{\text {storing }}=Q_{i}\left(13.16-2.13 \cdot \log \left(q_{n}\right)-\right. \\
& -S_{j}\left(1.85+93.35 S_{j}\right)
\end{aligned}
$$

where $Q_{i}$ - supply quantity, ton. $S_{j}$ - warehouse space, $\mathrm{m}^{2} ; j=1, \ldots, J$ - type of warehouse; $i=1, \ldots, I$ - material flow.

Estimation of warehouse space at store is calculated as [21]:

$S_{j}=\frac{q_{j}}{\delta_{a j} h_{j} a_{j}}$,

where $\delta_{a j}$ - average load per $1 \mathrm{~m}^{2}$ of the $j$-th store's warehouse area, ton $/ \mathrm{m}^{2} ; h_{j}$ - stock stowage height at $j$-th warehouse, m; $a_{j}$ - area utilization factor of the $j$-th warehouse; $j=1, \ldots, J$ - the specific store's warehouse area.

Determining the optimal economic order of goods delivery is a main step in the delivery of goods using the EOQ model, which depends directly on transportation costs, costs of storage in warehouse and supply quantity. In general, the optimal volume of delivery can be found by formula:

$$
\begin{aligned}
& Q_{t}^{E O Q}=\sqrt{\frac{2 \cdot q_{i} \cdot Z_{t}}{Z_{\text {storing }}}}= \\
& =\sqrt{\frac{\begin{array}{l}
2 \cdot q_{i} \cdot\left(\begin{array}{l}
l_{r} \cdot\left(0.113 \cdot q_{n}^{0.339}+0.067 \cdot R_{n}^{-0.092}\right)+ \\
+\frac{l_{r}}{v_{r}}\left(0.0015 \cdot q_{n}^{0.92}+0.0389 \cdot A^{-0.095}\right)
\end{array}\right) \\
q_{i} \cdot\left(13.165-2.13 \cdot \log \left(q_{i}\right)\right)+\frac{q_{i}}{\delta_{a j} \cdot h_{j} \cdot a_{j}} \times
\end{array}}{\times\left(1.85+93.35 \cdot\left(\frac{q_{i}}{\delta_{a j} \cdot h_{j} \cdot a_{j}}\right)^{-0.839}\right)}}
\end{aligned}
$$

When working with perishable goods, it is necessary to proceed from the condition of their expiration date. In this case, the quantity of delivery should not exceed the demand for products in a separate period:

$$
Q_{t}^{E O Q}=\left\{\begin{array}{l}
q_{i}>Q_{t}^{E O Q} \rightarrow q_{i}=Q_{t}^{E O Q} \cdot n_{t}^{\text {opt }} ; n_{t}^{\text {ord }} \geq 2 \\
q_{i}>Q_{t}^{E O Q} \rightarrow q_{i}=Q_{t}^{E O Q} \cdot n_{t}^{\text {opt }} ; n_{t}^{\text {ord }}=1 \rightarrow Q_{t}^{J I T},
\end{array}\right.
$$


Table 1 Range of variation data

\begin{tabular}{llcccc}
\hline No. & Factor & Symbol & Minimal & Average & Maximal \\
value & value & value \\
1 & Length of the route, $\mathrm{km}$ & $l_{r}$ & 5 & 20 & 35 \\
\hline 2 & Load capacity of a vehicle, ton & $q_{n}$ & 1.5 & 6 & 10.5 \\
3 & Specific fuel consumption of the vehicle, $1 / 100 \mathrm{~km}$ & $R_{n}$ & 11 & 18.5 & 26 \\
4 & Supply quantity, ton & $q_{i}$ & 0.5 & 2 & 3.5 \\
5 & Technical speed of a vehicle, $\mathrm{km} /$ hour & $v_{r}$ & 17 & 20 & 23 \\
6 & Area utilization factor of the $j$-th warehouse & $a_{j}$ & 0.4 & 0.7 & 1 \\
7 & Stock stowage height at the $j$-th warehouse, $\mathrm{m}$ & $h_{j}$ & 2 & 3.5 & 5 \\
8 & Average load per $1 \mathrm{~m}{ }^{2}$ of the $j$-th warehouse area, ton $/ \mathrm{m}^{2}$ & $\delta_{a j}$ & 0.4 & 0.7 & 1 \\
\hline
\end{tabular}

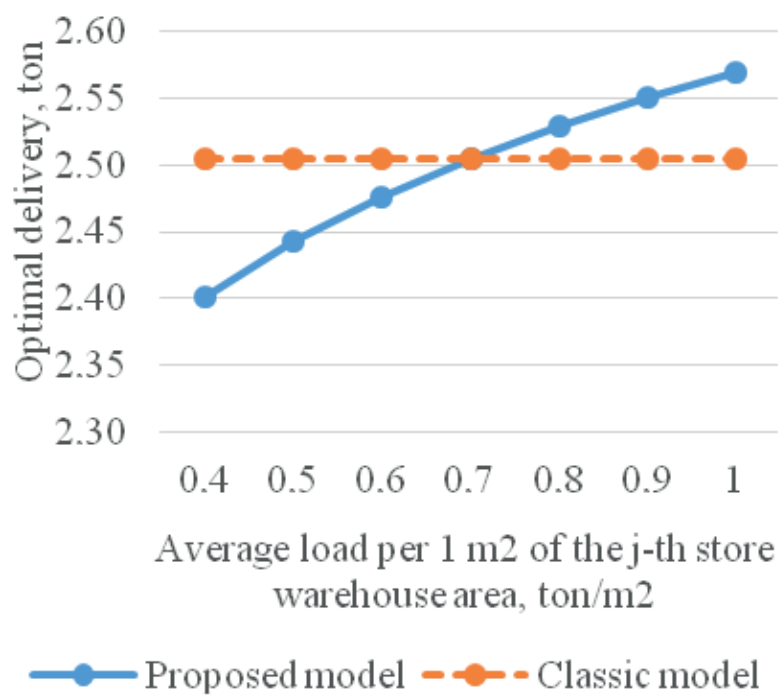

Figure 9 The change in the optimal delivery, depending on average load per $1 \mathrm{~m}^{2}$ of the $\mathrm{j}$-th warehouse

where $n_{t}^{\text {ord }}$ - number of restocking per period, times. $n_{t}^{o p t}$ - number of restocking for perishable goods with short validation range, times; $Q_{t}^{J I T}$ - everyday restocking quantity (JIT), ton.

Based on this circumstance, the demand amount was adjusted and the adjusted restocking was determined. The number of restocking in the period is calculated by the formula:

$n_{t}^{o r d}=q_{i} / Q_{t}^{E O Q}$

The number of restocking in the validation period of goods by EOQ model is calculated as:

$n_{t}^{o p t}=\frac{n_{t}^{\text {ord }} \cdot 365}{t_{w}}$

where $t_{w}$ - the validation time of the $j$-th product.

To compare the two models of goods delivery, the total costs per month for each model need to be calculated. For the EOQ model total costs per month can be found from:

$$
Z_{t}^{E O Q}=n_{t}^{o p t} \cdot Z_{t}+\left(\frac{Q^{o p t} \cdot t_{w}}{2}\right) \cdot Z_{\text {storing }} \cdot n_{t}^{o p t},
$$

where $t_{j}$ - time of storage in a warehouse, day.

For the JIT model total costs per month can be found from:

$Z_{t}^{J I T}=n_{t}^{o r d} \cdot Z_{t}+Z_{\text {storing }}$

For the efficiency estimate of using each of the systems, it is proposed to calculate the dependence:

$\frac{Z^{E O Q}}{Z^{J I T}}=\alpha_{E O Q / J I T}$.

If $\alpha_{E O Q / J T T}$ greater than 1, one needs to use the JIT model for deliveries, if it is less than 1 , then one needs to use the EOQ model, but if the ratio is close to 1 unit then it does not matter what technology of supplies to use.

\section{Results}

The proposed mathematical models were tested on a real example. For this, one of the retail chains in Kharkov was chosen, which is the largest there. The number of stores is 56 units. For now, restocking is made by simple routes 1-2 times per month (expectation 


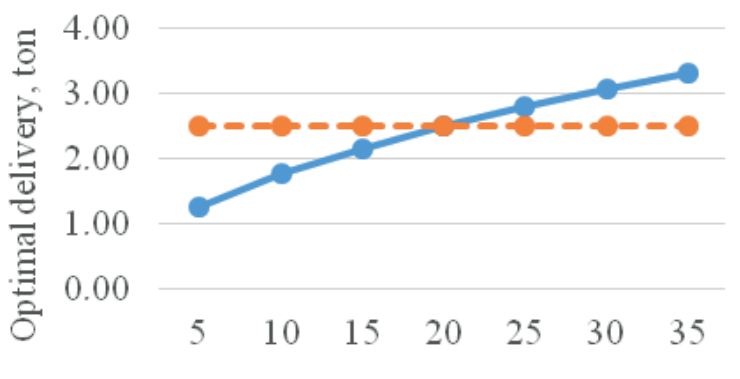

Length of the route, $\mathrm{km}$

$\longrightarrow$ Proposed model - - - Classic model

Figure 2 The change in the optimal delivery, depending on length of the route
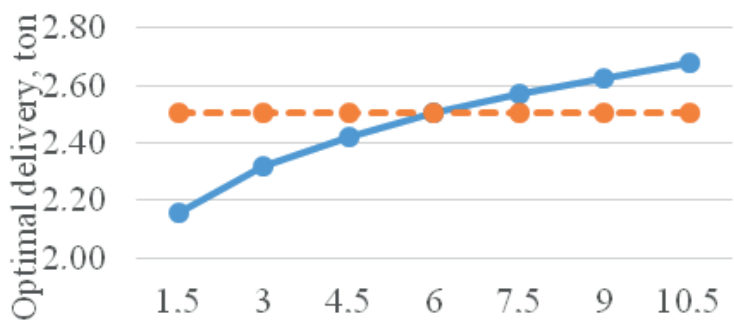

Load-carrying capacity of vehicle, ton

$\longrightarrow$ Proposed model - - - Classic model

Figure 3 The change in the optimal delivery, depending on the load-carrying capacity of vehicle

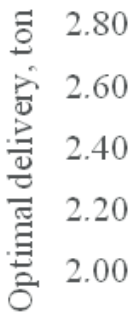

$\begin{array}{lllllll}11 & 13.5 & 16 & 18.5 & 21 & 23.5 & 26\end{array}$

Specific fuel consumption of the vehicle, $1 / 100 \mathrm{~km}$

$\longrightarrow$ Proposed model - - Classic model

Figure 4 The change in the optimal delivery, depending on the fuel consumption

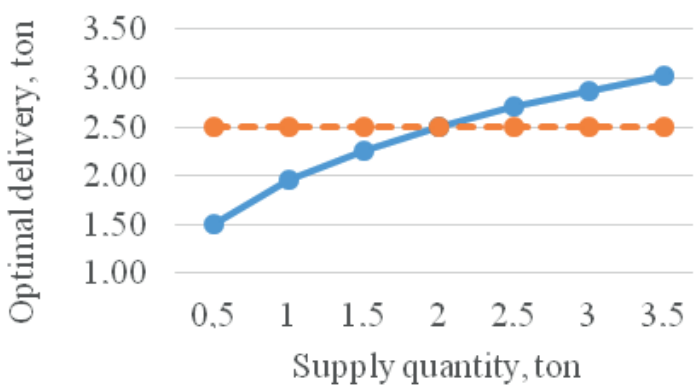

- Proposed model - - - Classic model

Figure 5 The change in the optimal delivery, depending on the supply quantity

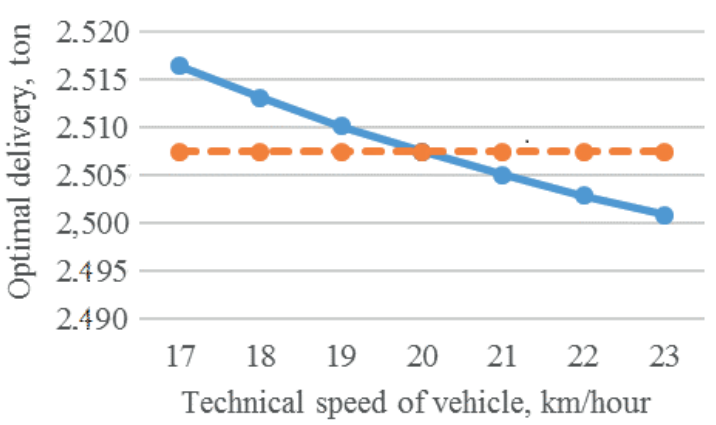

$\longrightarrow$ Proposed model $\quad-\bullet-$ Classic model

Figure 6 The change in the optimal delivery, depending on the vehicle's speed

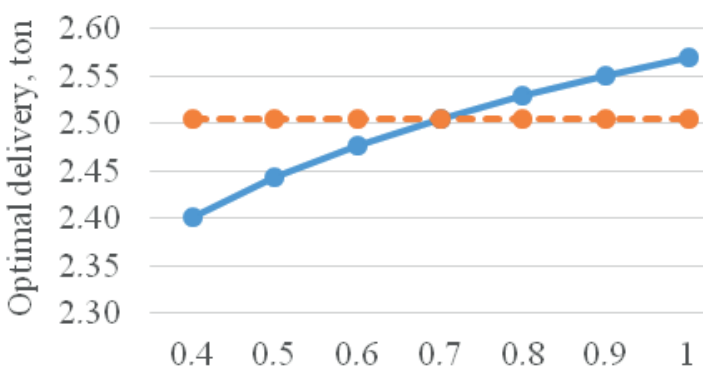

Area utilization factor $\mathrm{j}$-th warehouse $\longrightarrow$ Proposed model $-\rightarrow-$ Classic model

Figure 7 The change in the optimal delivery, depending on the area utilization factor of the $j$-th warehouse

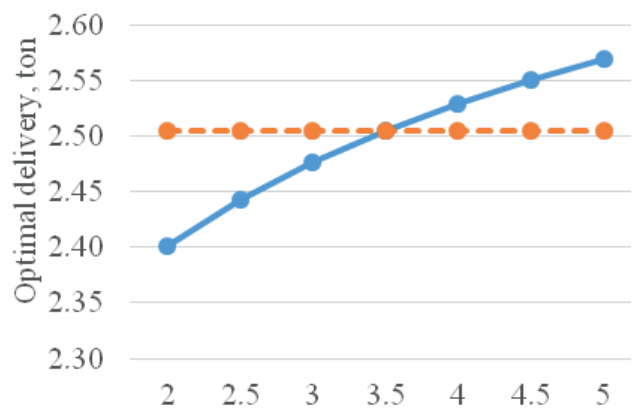

Stock stowage height at $\mathrm{j}$-th warehouse, $\mathrm{m}$

$\longrightarrow$ Proposed model $-\leadsto-$ Classic model

Figure 8 The change in the optimal delivery, depending on stock the storage height of $j$-th warehouse 
is goods with small validation period e.g. milk, bread, etc.) Collecting initial data and simulation established variation range of main parameters of the logistic activity, which are presented in Table 1.

For the visual impact of the parameters on the EOQ, graphs were constructed (Figures 2-9), with an average value of the optimal volume of delivery shown, as well.

From Figure 2, it can be seen that increasing the length of the route leads to increase in optimal delivery. As the transportation costs increase, it is more profitable for an enterprise to deliver more goods at one time less frequently.

Using the regression and correlation analysis, the set of model, which described the optimal quantity for delivery, was made. Model of change in the optimal delivery, depending on the route length is:

$Q_{t}^{E O Q}=0.336 l_{r}+1.067$.

The approximation confidence value is $R^{2}=0.983$.

Analysis of results of Figure 3 shows that increasing load-carrying capacity of vehicle leads to increase in optimal delivery. With increasing the load-carrying capacity, variable and constant costs increase. In order for the transportation costs to be reasonable, a proportional increase in the volume of delivery is required based on the carrying capacity of a vehicle.

Model of change in the optimal delivery, depending on the load-carrying capacity of a vehicle is:

$Q_{t}^{E O Q}=0.083 R_{n}+2.136$

The approximation confidence value is $R^{2}=0.956$.

As in Figure 3, increasing of fuel consumption in Figure 4 will increase volume of the optimal delivery, due to rising of variable costs. Figure 3 and 4 describe the indicator of the optimal amount of delivery in the same way, since an increase in one indicator proportionally increases another.

Model of change in the optimal delivery, depending on the fuel consumption is:

$Q_{t}^{E O Q}=0.083 R_{n}+2.136$

The approximation confidence value is $R^{2}=0.956$.

From Figure 5 can be seen that increasing the supply quantity will increase volume of the optimal delivery. The optimal delivery quantity can be higher than the actual supply quantity or lower, which indicates the direct impact of transportation and storage costs.

Model of change in the optimal delivery, depending on supply quantity is:

$Q_{t}^{E O Q}=0.245 q_{i}+1.422$

The approximation confidence value is $R^{2}=0.962$.

Analysis of Figure 6 shows that increasing the volume of vehicles speed leads to reducing the volume of optimal delivery. Increase in speed leads to decrease in transportation costs, which in turn increases gap between the storage and transportation costs. As a result, transportation costs become lower and more efficient to supply more often than to store in warehouse.

Model of change in the optimal delivery, depending on the vehicle's speed, is:

$Q_{t}^{o p t}=-0.0005 v+2.507$.

The approximation confidence value is $R^{2}=0.992$.

The Figure 7 shows that with increasing in area utilization factor, the efficiency of warehouse operations increases. It will also help reduce the costs of storing cargo and the expediency of using stocks.

Model of change in the optimal delivery, depending on area utilization factor:

$Q_{t}^{o p t}=-0.027 a_{j}+2.386$.

The approximation confidence value $R^{2}=0.981$.

From Figure 8 can be seen that increasing the stock stowage height leads to increase in optimal delivery. This can be explained by the fact that increase in space requires a proportional increase in the goods being delivered.

Model of change in the optimal delivery, depending on the stock stowage height, is:

$Q_{t}^{o p t}=0.027 h_{j}+2.386$.

The approximation confidence value is $R^{2}=0.981$.

Figure 9 shows that increasing the volume of average load per $1 \mathrm{~m}^{2}$ of store leads to increase in optimal delivery. This is quite logical, as an increase in stock filling requires the delivery of more goods.

Model of change in the optimal delivery, depending on the average load per $1 \mathrm{~m}^{2}$ of store, is:

$Q_{t}^{o p t}=0.027 \delta_{j}+2.386$

The approximation confidence value is $R^{2}=0.981$.

To compare the two models of goods delivery, the retailer and supplier were chosen, which are located in Kharkiv (Figures 10-11). All the initial data are presented in Table 1.

According to marketing research that was carried out earlier, the volumes of material flows that are bought by consumers per day were set. In the case of the JIT model the suppling of goods is carried out each day per month in needed quantity. Therefore, there are only transportation costs. In Figure 12 is presented an example of supplying to the retailer by the JIT model.

In the case of Economic Order Quantity (EOQ), the model of the suppling of goods is carried out based on the optimal delivery volume in needed quantity. Therefore, there are transportation costs and costs of storage in a warehouse. In Figure 13 is shown an example of 


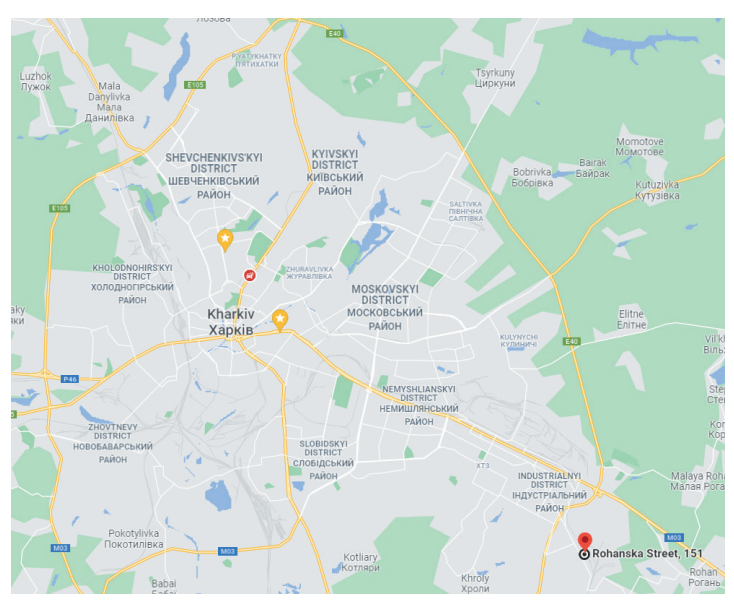

Figure 10 Location of the supplier

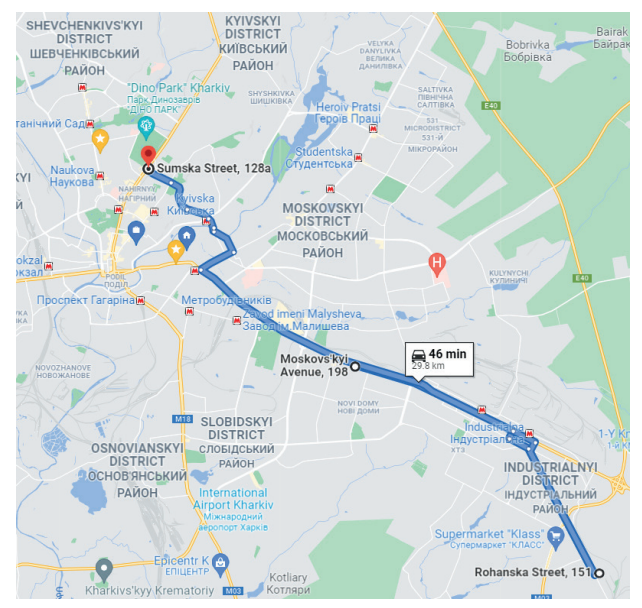

Figure 11 Transportation process to the retailer

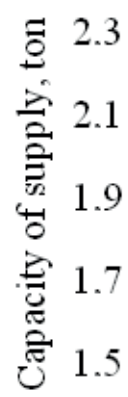

1223445667589101112131415161718192021222324252627282930

Days of month, day

Figure 12 Capacity of the warehouse in store by JIT model

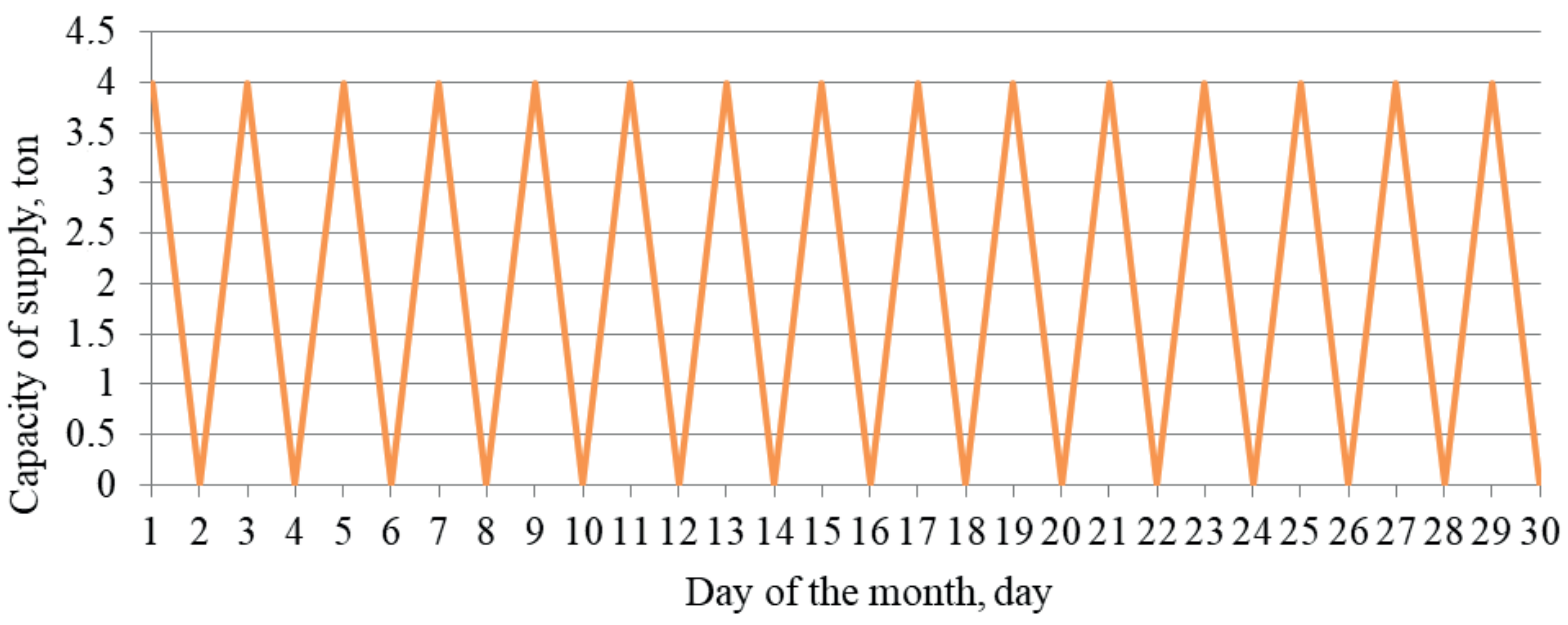

Figure 13 Capacity of the warehouse in store by the EOQ model

Table 2 Indicators of using the restocking technologies

\begin{tabular}{lcc}
\hline Model & $\begin{array}{c}\text { Total expenses for restocking of material } \\
\text { flows by just-in-time model, } \\
\text { EUR/month }\end{array}$ & $\begin{array}{c}\text { Total expenses for restocking of material flows by } \\
\text { Economic Order Quantity (EOQ) model, } \\
\text { EUR/month }\end{array}$ \\
\hline Total costs & 5702.73 & 10124.72 \\
\hline
\end{tabular}

supplying to the retailer by EOQ model. Analysis of the two graphs shows every day restocking (JIT) do not change level of sock in store, instead of EOQ when supply made in periods of time. It shows fluctuations of stock during the month and variety of costs to maintain the stock. 
After calculation by Equations (1) - (10) the total costs for each of the two logistic models, are shown in Table 2.

As analysis of the proposed model shows, the costs of delivering a new shipment of goods to the warehouse significantly affect the economical size of the order, so in reality, using Equation (6) can significantly increase definition of the economical size of the order.

According to Equation (12) $\alpha_{E O Q / J I T}$ is greater than 1:

$\alpha_{E O Q / J I T}=\frac{10124.72}{5702.02}=1.7$

Therefore, the more efficient is to use the JIT technology for restocking in this case. It takes less costs for 1.7 times for this distribution network.

Logistical inventory management has a number of requirements: the quantity of the stock must be sufficient to ensure the continuity of the production and circulation processes. The stock should be reduced, as much as possible and its mobility should be as high as possible. The costs associated with the storage of stocks, should strive to be minimized, which should ensure the reduction of losses from the immobilization of working capital in stocks

\section{Discussion}

In the classic EOQ and JIT models, the parameters remain fixed, only the quantity changes. In reality, the costs of transportation and storage will depend on the scope of supply. Thus, the existing patterns indicate a decrease in the costs of transportation of a unit of production with an increase in the load-lifting capacity of ta vehicle. Fixed costs in stock remain fixed for a month, but with an increase in warehouse turnover, the share of these costs in total logistics costs for product promotion decreases.

The proposed coefficient determines the feasibility of using a particular supply technology. In this paper, the costs of using technology were considered, but by using a different system of restrictions (for example, profit from sales), other results could be obtained.

The presented results are relevant for the selected range of data collected in Ukraine; if the range of data is changed, the results can be changed. Nevertheless, the results obtained do not in any way contradict the dependencies already obtained in $[1,16,21]$ and even add to them. The approach to costs comparison of different delivery models is the original scientific novelty of this article. The approach can be used in various interpretations, depending on the prevailing environmental conditions. For instance, described above scenario has one supplier many retailer option. There can be other variations: one retailer from more supplier, many suppliers to many retailers, which can be described in further works in context of the JIT and EOQ restocking comparison. the features of the logistics system, the features of management systems by adding new elements and parameters to existing ones or their modifications.

\section{Conclusions}

The article presents an approach to determining the comparison in organizing supplies to the retailer. For this, the two supply models were compared. The Just-in-Time (JIT) model is characterised by costs that are spend on transportation. The Economic Order Quantity (EOQ) model includes costs of transportation and storage in a warehouse. After calculations, it was determined that use of the Just-in-Time model would be more profitable in the given conditions.

The optimal order quantity is determined, opposed to previously obtained models; the proposed model takes into consideration influence of the technological indicators of warehouse and transport processes on replenishment of stocks, on the one hand and the size of the order - on the other hand. Using the developed model would provide a more accurate calculation of the order size, which would maximally reduce the costs of inventory management, while respecting the guaranteed delivery to customers.

\section{References}

[1] ASADABADI, M. A revision on EOQ/JIT indifference points. International Journal of Industrial Engineering Computations. 2015, 6(3), p. 305-314. ISSN 1923-2926, eISSN 1923-2934.

[2] SHEPELEV, V., ALMETOVA, Z., LARIN, O., SHEPELEV, S., ISSENOVA, O. Optimization of the operating parameters of transport and warehouse complexes. Transportation Research Procedia [online]. 2018, 30, p. 236244. ISSN 2352-1465. Available from: https://doi.org/10.1016/j.trpro.2018.09.026

[3] ALMETOVA, Z., SHEPELEV, V., MAKAROVA, I., SHEPELEVA, E., GRITSENKO, A. Methodical framework for evaluating the level of the carrying capacity of transport systems in view of the irregularity of cargo flows. Transportation Research Procedia [online] 2018, 30, p. 226-235. ISSN 2352-1465. Available from: https://doi.org/10.1016/j.trpro.2018.09.025

[4] MAKAROVA I., SHUBENKOVA K., PASHKEVICH A. Logistical costs minimization for delivery of shot lots by using logistical information systems. Procedia Engineering [online]. 2017, 178, p. 330-339. ISSN 1877-7058. Available from: https://doi.org/10.1016/j.proeng.2017.01.059 
[5] AULIN, V., HRYNKIV, A., LYASHUK, O., VOVK, Y., LYSENKO, S., HOLUB, D., ZAMOTA, T., PANKOV, A., SOKOL, M., RATYNSKYI, V., LAVRENTIEVA, O. Increasing the functioning efficiency of the working warehouse of the "UVK Ukraine" company transport and logistics center. Communications - Scientific Letters of the University of Zilina [online]. 2020, 22(2), p. 3-14. ISSN 1335-4205, eISSN 2585-7878. Available from: https://doi.org/10.26552/com.C.2020.2.3-14

[6] WILSON, R. H. A scientific routine for stock control. Harvard Business Review. 1943, 13(1), p. 116-128. ISSN 0017-8012.

[7] MIN, W., SUI PHENG, L. EOQ, JIT and fixed costs in the ready-mixed concrete industry. International Journal of Production Economics [online]. 2006, 102(1), p. 167-180. ISSN 0925-5273. Available from: https://doi.org/10.1016/j.ijpe.2005.03.002

[8] KUCERA, T. Application of the activity-based costing to the logistics costs calculation for warehousing in the automotive industry. Communications - Scientific Letters of the University of Zilina [online]. 2019, 21(4), p. 35-42. ISSN 1335-4205, eISSN 2585-7878. Available from: https://doi.org/10.26552/com.C.2019.4.35-42

[9] CHYR, F., LIN, T. M., HO, C. F. Comparison between Just-In-Time and EOQ system. Engineering Costs and Production Economics [online]. 1990, 18(3), p. 233-240. ISSN 0167-188X. Available from: https://doi.org/10.1016/0167-188X(90)90125-2

[10] WANG, S., YE, B. A comparison between just-in-time and economic order quantity models with carbon emissions. Journal of Cleaner Production [online]. 2018, 187, p. 662-671. ISSN 0959-6526. Available from: https://doi.org/10.1016/j.jclepro.2018.03.218

[11] FAZEL, F. A comparative analysis of inventory costs of JIT and EOQ. International Journal of Physical Distribution and Logistics Management [online]. 1997, 27(8), p. 496-505. ISSN 0960-0035. Available from: https://doi.org/10.1108/09600039710182680

[12] MIN, W., PHENG, L. S. EOQ with a price discount versus JIT purchasing: an alternative analysis in the readymixed concrete industry. Journal of Construction Research [online]. 2005, 6(01), p. 47-69. ISSN 1609-9451, eISSN 1793-687X. Available from: https://doi.org/10.1142/S1609945105000262

[13] SCHNIEDERJANS, M. J., CAO, Q. An alternative analysis of inventory costs of JIT and EOQ purchasing. International Journal of Physical Distribution and Logistics Management [online]. 2001, 31(2), p. 109-123. ISSN 0960-0035. Available from: https://doi.org/10.1108/09600030110387507

[14] JOSHI, K., CAMPBELL, J. F. Managing inventories in a JIT environment. International Journal of Purchasing and Materials Management [online]. 1991, 27(2), p. 32-36. eISSN 1745-493X. Available from: https://doi. org/10.1111/j.1745-493X.1991.tb00531.x

[15] KUBASAKOVA, I., JAGELCAK, J. Logistics system Just-In-Time and its implementation within the company. Communications - Scientific Letters of the University of Zilina [online]. 2016, 18(2), p. 109-112. ISSN 1335-4205, eISSN 2585-7878. Available from: http://komunikacie.uniza.sk/index.php/communications/article/view/340

[16] CHEBANYUK, K., GALKIN, A., LOBASHOV, O., OSTASHEVSKYI, S., PSOL, S., SHVETS, R., SABADASH, V. Urban freight restocking tours simulations for JIT and EOQ. In: 33rd International Business Information Management Association Conference IBIMA 2019: proceedings. Vol. 33. 2019. p. 5920-5930.

[17] GALKIN, A., OLKHOVA, M., IWAN, S., KIJEWSKA, K., OSTASHEVSKYI, S., LOBASHOV, O. Planning the rational freight vehicle fleet utilization considering the season temperature factor. Sustainability [online]. 2021, 13(7), 3782. eISSN 2071-1050. Available from: https://doi.org/10.3390/su13073782

[18] LITOMIN, I., TOLMACHOV, I., GALKIN, A. Use of the distribution center in the Ukrainian distribution system. Transportation Research Procedia [online], 2016, 16, p. 313-322. ISSN 2352-1465. Available from: https://doi. org/10.1016/j.trpro.2016.11.030

[19] KUSH, Y., SKRYPIN, V., GALKIN, A., DOLIA, K., TKACHENKO, I., DAVIDICH, N. Regularities of change of the supply chain operation efficiency, depending on the parameters of the transport process. Transportation Research Procedia [online]. 2018, 30, p. 216-225. ISSN 2352-1465. Available from: https://doi.org/10.1016/j. trpro.2018.09.024

[20] SKRYPIN, V. S. Organization of the transport process for conveying of packaged goods by points of sale on the principles of logistics [online]. Ph.D. thesis. Kharkiv: O. M. Beketov National University of Urban Economy in Kharkiv, 2017. Available from: https://radats.kname.edu.ua/images/Files/dis_Skripin.pdf

[21] OLKHOVA, M., ROSLAVTSEV, D., GALKIN, A. The comparative method of assessing city logistics measure. In: Decision support methods in modern transportation systems and networks. Lecture notes in networks and systems. Springer, 2021. p. 163-174. ISBN 978-3-030-71770-4 